2020-03-02

\title{
Mirror, Mirror on the Wall: The Effect of Listening to Body Positive Music on Implicit and Explicit Body Esteem
}

\author{
Sarah M. Coyne \\ Brigham Young University - Provo, smcoyne@byu.edu \\ Emilie J. Davis \\ Brigham Young University - Provo \\ Wayne Warburton \\ Macquarie University \\ Laura Stockdale \\ Brigham Young University - Provo \\ Imogen Abba

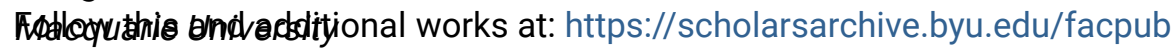 \\ Part of the Other Social and Behavioral Sciences Commons
}

See next page for additional authors

Original Publication Citation

Coyne, S. M., Davis, E. J., Warburton, W., Stockdale, L., Abba, I., \& Busby, D. M. (2020, March 2). Mirror, Mirror on the Wall: The Effect of Listening to Body Positive Music on Implicit and Explicit Body Esteem. Psychology of Popular Media. Advance online publication.

\section{BYU ScholarsArchive Citation}

Coyne, Sarah M.; Davis, Emilie J.; Warburton, Wayne; Stockdale, Laura; Abba, Imogen; and Busby, Dean M., "Mirror, Mirror on the Wall: The Effect of Listening to Body Positive Music on Implicit and Explicit Body Esteem" (2020). Faculty Publications. 4123.

https://scholarsarchive.byu.edu/facpub/4123

This Peer-Reviewed Article is brought to you for free and open access by BYU ScholarsArchive. It has been accepted for inclusion in Faculty Publications by an authorized administrator of BYU ScholarsArchive. For more information, please contact ellen_amatangelo@byu.edu. 
Authors

Sarah M. Coyne, Emilie J. Davis, Wayne Warburton, Laura Stockdale, Imogen Abba, and Dean M. Busby

This peer-reviewed article is available at BYU ScholarsArchive: https://scholarsarchive.byu.edu/facpub/4123 


\section{Psychology of Popular Media}

\section{Mirror, Mirror on the Wall: The Effect of Listening to Body Positive Music on Implicit and Explicit Body Esteem}

Sarah M. Coyne, Emilie J. Davis, Wayne Warburton, Laura Stockdale, Imogen Abba, and Dean M. Busby

Online First Publication, March 2, 2020. http://dx.doi.org/10.1037/ppm0000273

\section{CITATION}

Coyne, S. M., Davis, E. J., Warburton, W., Stockdale, L., Abba, I., \& Busby, D. M. (2020, March 2). Mirror, Mirror on the Wall: The Effect of Listening to Body Positive Music on Implicit and Explicit Body Esteem. Psychology of Popular Media. Advance online publication.

http://dx.doi.org/10.1037/ppm0000273 


\title{
Mirror, Mirror on the Wall: The Effect of Listening to Body Positive Music on Implicit and Explicit Body Esteem
}

\author{
Sarah M. Coyne and Emilie J. Davis \\ Brigham Young University \\ Laura Stockdale \\ Brigham Young University
}

\author{
Wayne Warburton \\ Macquarie University \\ Imogen Abba \\ Macquarie University
}

\author{
Dean M. Busby \\ Brigham Young University
}

\begin{abstract}
The current article used 3 studies to examine the impact of listening to body positive music on both explicit and implicit measures of body esteem in women. Study 1 found that women who viewed a mainstream popular body positive music video reported higher levels of body esteem than those who viewed a popular body objectifying music video. In Studies 2 and 3, we wrote and recorded our own songs to keep the musical features apart from the lyrics constant (e.g., rhythm, melody, and singer identity). Study 2 also found that women showed higher levels of implicit (but not explicit) body esteem when watching a music video portraying body positive lyrics as compared with objectifying lyrics. Study 3 added a neutral song and examined a number of moderators. There were few differences between those listening to the body positive and neutral lyrics, but those who listened to objectifying compared with neutral lyrics had lower body esteem. Moderation revealed that women who had preexisting low body esteem showed lower implicit body esteem after listening to any appearance-related music compared with those who listened to neutral lyrics. Thus, we recommend that women choose to listen to body positive lyrics over objectifying ones and to avoid appearance-related songs if they are prone to body esteem concerns.
\end{abstract}

\section{Public Policy Relevance Statement}

Women who listen to body positive music tend to have higher body esteem than those who listen to body objectifying music. However, women who have prior body image concerns tend to have worse body esteem after listening to any appearance-related music (either positive or negative).

Keywords: music, body image, media, music video, body esteem

Body esteem, or how we view our bodies, is an essential component of identity development (Nelson, Kling, Wängqvist, Frisén, \& Syed, 2018). The vast majority of research has examined

Sarah M. Coyne and Emilie J. Davis, School of Family Life, Brigham Young University; (D) Wayne Warburton, Department of Psychology, Macquarie University; Laura Stockdale, School of Family Life, Brigham Young University; Imogen Abba, Department of Psychology, Macquarie University; (D) Dean M. Busby, School of Family Life, Brigham Young University.

We would like to acknowledge Colbie Caillat for inspiring this study. We also thank Bianka Toto, Sonia David, Noemi Genua, Brooke Grech, and Rachel Thompson, whose assistance in writing and recording the songs used in Studies 2-3 was greatly appreciated.

Correspondence concerning this article should be addressed to Sarah M. Coyne, School of Family Life, Brigham Young University, JFSB 2086C, Provo, UT 84602. E-mail: smcoyne@byu.edu the development of poor body esteem (Dohnt \& Tiggemann, 2006; Nelson et al., 2018), with a focus on how media portrays an unrealistic view of women's bodies (Conley \& Ramsey, 2011; Grabe, Ward, \& Hyde, 2008; Nelson et al., 2018). Adolescents and emerging adult women tend to be particularly vulnerable to developing body image concerns as compared to older women. Additionally, White women tend to have lower body esteem than non-White women (Molloy \& Herzberger, 1998) and show stronger media-related effects, likely because the media tends to specifically overemphasize the thin-ideal for White women (Schooler, Ward, Merriwether, \& Caruthers, 2004).

However, there is a growing line of literature suggesting that parents and educators should actively be teaching body positivity, instead of just focusing on how to prevent body dissatisfaction (Crawshaw, 2019; Tylka, 2011). Body positivity is a related, but distinct, construct to body dissatisfaction. Tylka and WoodBarcalow (2015) defined body positivity as a multifaceted construct that involves the development of a positive body esteem that 
goes beyond simply how the body looks. Instead, body positivity involves body appreciation, with a focus on how the body feels, functions, and what it can do. Women with higher body esteem tend to appreciate the unique beauty of their bodies, value their bodies' functionality, filter media ideals (i.e., question the authenticity of the portrayal of women in media), have a broader view of beauty, and emphasize their bodies' assets while minimizing perceived flaws (Tiggemann \& McCourt, 2013; Wood-Barcalow, Tylka, \& Augustus-Horvath, 2010).

In recent years, there has been a "body positivity" movement from many in the media industry (Sastre, 2014), where women are encouraged to reject the unrealistic expectations placed upon them by society. However, there is very little research on the impact of the body positivity media movement on body esteem in women, so it is unclear whether such messages are effective in encouraging a positive body esteem. In the current study, we examine body positivity in music lyrics, a medium in which there is anecdotally an increase in body positive messages for women. The current article consists of three experimental studies examining the impact of exposure to body positive music lyrics on body esteem in emerging adult women.

\section{Body Positivity and Media}

The vast majority of research on media and body esteem has focused on how media might influence body dissatisfaction. For example, exposure to media images promoting the thin ideal and sending the message that women's value is predominantly in their appearance is associated with a number of negative outcomes, including poor body esteem, poor self-esteem, depression, increased dieting, and a greater propensity for eating disorders (Grabe et al., 2008; Harper \& Tiggemann, 2008), and lower levels of positive body esteem (Karsay, Trekels, Eggermont, \& Vandenbosch, 2018).

Just as unrealistic portrayals in media are associated with decreased body esteem in media consumers, prohealthy, diverse, and body positive-based media messages can encourage better body esteem (Bissell \& Rask, 2010). Research on body positivity in media is rare. A few early studies focused on advertisements that emphasized body appreciation and uniqueness. For example, one study tested the "Dove Campaign for Real Beauty" and found that viewing the videos was effective in influencing the way women perceived beauty in society (Bissell \& Rask, 2010). Most research on body positivity and media has focused on social media. Such messages are common on social media being shared by news organizations, influencers, and women themselves. The posts show a range of diverse body shapes, with most posts aligning with the academic research on body positivity in terms of messaging (Cohen, Irwin, Newton-John, \& Slater, 2019). Women tend to like body positivity social media posts and feel better about their body after viewing these posts (although they were also more likely to self-objectify as well; Cohen, Fardouly, Newton-John, \& Slater, 2019; Slater, Varsani, \& Diedrichs, 2017). However, some research suggests that although such posts may have a positive effect on body image, some corporations used this approach for capital gain, specifically pushing their own products (Cwynar-Horta, 2016). Thus, the impact of body positivity in media is likely mixed. Though this research suggests that positive body messages are common, at least in social media, and that they potentially have a positive impact, no research has examined these messages in music.

\section{Body Positivity and Music}

Music is the second most used form of media for 8-to-18-yearolds (i.e., TV being first; Rideout, 2015), and researchers have argued it is more important than any other media type in managing mood and expressing identity (Lonsdale \& North, 2011). A number of high-profile musical artists have released songs that align well with the body positivity movement. Singers like Christina Aguilera, Colbie Caillat, and Alessia Cara have begun writing songs like "Beautiful," "Try," and "Scars to Your Beautiful" to combat the rampant standard of the thin ideal present in media. These songs have been well received by fans (Billboard, 2016; Empire, 2016), reaching gold and platinum in sales, yet little empirical work has examined the effects of such song lyrics on body esteem.

Though research has not examined how body positivity messages in music might impact body esteem, several studies have found that exposure to both music videos and lyrics can impact women's attitudes and behavior (Coyne et al., 2019). First of all, there is a literature suggesting that music can impact both explicit and implicit self-esteem in general (Elvers, Fischinger, \& Steffens, 2018), with women in particular using music for empowerment and personal growth (Travis, Bowman, Childs, \& Villanueva, 2016). Content analyses suggest that women's bodies are routinely objectified in music lyrics (Aubrey \& Frisby, 2011; Flynn, Craig, Anderson, \& Holody, 2016). Other research suggests that music lyrics tend to be even more important than musical tone in predicting listener behavior, suggesting that the message matters (Lennings \& Warburton, 2011). Thus, it is likely that music which has body positive lyrics might impact women's body esteem. Additionally, videos often accompany music lyrics and are extremely popular with listeners, often obtaining millions of views. Seeing a singer with a particular body shape might impact the viewer over and above listening to lyrics without any appearancebased cues. A host of studies suggest that music videos in particular might influence the way that women feel about their bodies (see Wright et al., 2018, 2019, for reviews). For example, viewing sexually objectifying music videos is associated with higher selfobjectification and body dissatisfaction in women (Karsay \& Matthes, 2016; Mischner, van Schie, Wigboldus, van Baaren, \& Engels, 2013; Zhang, Dixon, \& Conrad, 2009). Additionally, exposure to models epitomizing the thin-ideal in music videos is related to body dissatisfaction in adolescent girls (Bell, Lawton, \& Dittmar, 2007). Thus, it is likely that viewing body positive music videos and listening to body positivity music lyrics may impact body esteem in women.

\section{Theoretical Approach}

There are three main theories that may inform the study. First, objectification theory (Fredrickson \& Roberts, 1997) suggests that experiences at the sociocultural level (including the mass media) may influence several risk factors that may interfere with the development of positive body esteem. According to the theory, self-objectification is the primary route through which media might impact body esteem. Self-objectification is characterized by 
viewing the body as an object, with a focus on physical beauty as a primary driver of an individual's sense of self and value. The body positivity movement (and body positivity messages specifically in music) encourages individuals to reject the assumption that the body is an object, only valuable for its appearance. According to this theory, it is likely that listening to music that provides a body positive message, where the importance of attaining a particular beauty ideal is deemphasized, may result in lower levels of self-objectification and higher levels of body esteem.

Additionally, the general learning model (GLM) explains how viewing any type of behavior in media might influence behaviors (Buckley \& Anderson, 2006). This theory has predominantly focused on how viewing positive messages in media (such as prosocial behavior) might influence positive outcomes for viewers, such as increased helping behavior, empathy, or a decrease in aggressive behavior (Coyne et al., 2018). The current study does not examine prosocial behavior specifically, but it does examine positive messages in media. The theory describes how exposure to positive media messages might influence behavior and attitudes in both the short- and long term. Theoretically, exposure to body positive music lyrics may influence a person's internal state in three specific ways. Viewing such material might influence one's affect, by helping them to get in a good mood by encouraging positive emotion (also see the broaden-and-build theory in the following text); their arousal, by lowering blood pressure and decreasing cortisol; and their cognition, by activating body positive-related scripts in memory. According to the GLM, this internal state may impact feelings toward one's own body, which then may influence other body-related behaviors, such as dieting or other eating behavior (though we do not examine these in the current study). Theoretically, listening to body positive lyrics in music may create and strengthen cognitive scripts in memory that are body positive, leading to better body esteem throughout life, though this is not examined in the current study. This is certainly the case with other positive media, such as media with a focus on the development of prosocial behavior and empathy (Coyne et al., 2018). We focus on short-term effects in the current study.

Finally, body positivity might be well situated in the positive psychology theories. Broadly, positive psychology seeks to understand and foster attributes and experiences that help individual flourish (Seligman \& Csikszentmihalyi, 2014). Developing a positive body image, and using body positive media messages to do so, falls within this scope. The broaden-and-build theory is particularly relevant to the current study (Fredrickson, 2001). This theory suggests that positive experiences (such as listening to body positive music) might broaden individual's thought-action repertoires (including many of the internal states described in the GLM), which then might provide the individual with a host of positive resources to draw upon in the future. Thus, applied to the current study, listening to body positive music might broaden an individual's view of their own body and capacities.

\section{Aims and Hypotheses}

The primary aim of the current study was to examine the impact of body positive and objectifying lyrics on women's explicit and implicit body esteem. We examined this in three experimental studies, using multiple media (including those publicly produced and those we produced ourselves), and using both music lyrics and lyrics combined with music videos. According to both the GLM and self-objectification theory, we anticipate that exposure to body positive lyrics will be positively related to higher explicit and implicit measures of body esteem as compared with body objectifying or neutral lyrics.

\section{Study 1 (Feasibility Study)}

\section{Method}

The purpose of Study 1 was to examine the impact of exposure to body positive lyrics on body esteem in women. This study was small in nature, though the aim was to provide external validity to build on with the next two studies.

Participants and procedures. Participants consisted of 43 women between the ages of 19 and $26(M=23.21, S D=1.90)$ from the United States. Approximately $63 \%$ of the sample was Caucasian, with 16\% African American, 12\% Hispanic, 5\% Asian American, and 5\% multiethnic or another ethnicity. Participants were recruited from Amazon Mechanical Turk (MTurk), which is a website designed to recruit "workers" from around the world to complete specific tasks for a small monetary reward (\$2). Regarding the current project, a job was posted inviting women to take part in a study on music and wellness. Participants were told that they were participating in a study on "music and wellness" and would view a video and then complete a series of questionnaires. Only English-speaking women between the ages of 18 and 26 were invited to take part in the study. Scholars have noted that the population of MTurk tends to be like other research populations, and several studies have been replicated using MTurk, showing its reliability as a research tool (Paolacci, Chandler, \& Ipeirotis, 2010).

\section{Measures and materials.}

Video. Participants were randomly assigned to view one of two music videos, either containing body positive or objectifying lyrics. The body positive music video was "Try" by Colbie Caillat. The video involves a series of women of all different ages (including Colbie Caillat herself) taking off their makeup, hair extensions, false eyelashes, and so forth, and being happy with their true selves. The lyrics are focused on body positivity encouraging women to love their body, regardless of shape or size.

The body objectifying video was "Good for you" by Selena Gomez. The video features Selena in various outfits singing about how she wants to "look good" for someone else. The importance of physical appearance and being physically attractive are expressed throughout the song.

In terms of condition, 23 participants viewed the body objectifying condition and 20 viewed the body positive condition. A number of attention checks were integrated into the study to ensure that participants were paying attention to both the video and the questionnaire (with no participant needing to be dropped from the study). Immediately after viewing one of these two videos, participants completed a number of measures described in the following text. A power analysis revealed that this sample had a power $=.81$ in detecting a medium effect size.

Fourteen coders $\left(M_{\text {age }}=22.21, S D=.80,50 \%\right.$ female $)$ viewed and rated both music videos on how body positive each video was on a 5-point scale ranging from 1 (extremely body objectifying) to 5 (extremely body positive). Body objectifying was defined as 
"messages that focus on the appearance of the body as important for self or others, or that portrays the body in a negative light," and body positive was defined as "messages that focus on loving the body regardless of physical appearance" (note: these same definitions were used in Studies 2 and 3 as well). A paired samples $t$ test revealed that coders rated the Colbie Caillat $(M=4.57, S D=.51)$ video as being significantly more body positive than the Selena Gomez $(M=1.57, S D=.51)$ video, $t(13)=12,80, p<.001$. Interclass correlations between coders were ICC $=.95$.

Body esteem and body satisfaction measures. Body image is a complex, multidimensional construct. Accordingly, we examine this in a number of ways as described in the following text.

Body esteem. Body esteem was measured using items from the Body Esteem Scale for Adolescents and Adults-Modified (Mendelson, Mendelson, \& White, 2001). Participants were asked to indicate how much they agreed with 23 statements using a 5-point Likert-type scale ranging from 1 (never) to 5 (always). There were three subscales used in the current study. General body esteem was measured with 11 items (e.g., "I like what I see when I look in the mirror") and showed acceptable reliability $(\alpha=.93)$. "Other body image" involved statements that indicated how other people would view the individual, based on their appearance. This was measured with six items (e.g., "other people consider me good looking") and showed acceptable reliability $(\alpha=.77)$. Finally, "weight body image" involved items that specifically measured how the individual felt about their body weight. This was measured using six items (e.g., "I really like what I weigh") and also showed acceptable reliability $(\alpha=.92)$. Higher scores indicate higher body esteem for each subscale. See Mendelson, Mendelson, and White (2001) for further description of the reliability and validity of this measure.

Body satisfaction. Body satisfaction was measured using eight items asking participants to rate how satisfied they were with a series of body parts (e.g., lower torso [buttocks, hips, thighs, legs]; mid torso [waist, stomach]; upper torso [breasts, shoulders, arms]) on a 5-point Likert scale ranging from 1 (very dissatisfied) to 5 (very satisfied; Cash, 2015). Initial reliability was very low ( $\alpha=$ .10). An examination of the scale revealed that two items (Face [facial features, complexion] and Hair [color, thickness, texture]) were significantly bringing the reliability down; accordingly, these two items were dropped. The final six items were averaged, with higher scores indicating higher levels of body satisfaction. The final scale showed acceptable reliability $(\alpha=.92)$. See Cash (2015) for further description of the reliability and validity of this measure.

Eating disorder tendencies. Participants first completed a scale measuring eating disorder tendency (Cotton, Ball, \& Robinson, 2003). Participants were asked to mark "yes" or "no" to five questions (e.g., "Do you currently suffer with or have you ever suffered in the past with an eating disorder?"). As required by our institutional review board, participants answering "yes" to three or more items were paid in full, referred to professionals for help, but excluded from participating in the study. According to Cotton et al. (2003), a cutoff score of 3 was $100 \%$ effective in detecting an eating disorder among women.

Music time. Participants also rated how frequently they listened to music on a daily basis on a 6-point Likert scale ranging from 1 (none) to 6 (more than $3 \mathrm{hr}$ a day). This was used as a covariate in the analysis.

\section{Results}

All body esteem and image measures were significantly correlated with each other (all comparisons were $p<.001$ ). A multivariate covariance analysis of variance (MANCOVA) was conducted, controlling for ethnicity and daily time spent listening to music. Participants who viewed the body positive music video reported better other body esteem, $F(1,43)=6.70, p=.013, \eta_{\mathrm{p}}^{2}=$ .15 , and weight body esteem, $F(1,43)=4.75, p=.035, \eta_{\mathrm{p}}^{2}=.11$, than those who viewed the body objectifying music video. However, there was no difference for the body esteem general measure ( $p=.13$ ) or the body satisfaction measure $(p=.06)$, though means were both in the expected direction. Control variables did not predict any outcome measure. See Table 1 for means and standard deviations for each condition.

\section{Discussion}

This study showed that listening to a music video with body positive music video resulted in higher body esteem (according to some measures) than listening to music with body objectifying lyrics. However, the sample was relatively small, and there were many confounds between the two videos such as the tempo, melody, dynamics, setting, tone of the music, identity of the singer, images portrayed in the video, and so forth. The purpose of Study 2 was to continue to examine the impact of music videos on body image but with stimuli that we created ourselves. This enabled us to control extraneous features of the music video to control for confounds as previously listed.

\section{Study 2}

\section{Method}

Participants. A power analysis revealed that at least 179 participants were needed overall to detect a medium size effect $(d=.50)$ with $95 \%$ power. Participants consisted of 185 women aged $18-25$ years old $(M=20.25, S D=1.96)$ from the Western United States. Approximately $90 \%$ were Caucasian and the other $10 \%$ classified themselves as African American, Hispanic, Asian

Table 1

Means and Standard Deviations for Main Variables by Music Video Condition-Study 1

\begin{tabular}{|c|c|c|c|c|}
\hline \multirow[b]{3}{*}{ Outcome } & \multicolumn{4}{|c|}{ Condition } \\
\hline & \multicolumn{2}{|c|}{$\begin{array}{c}\text { Body } \\
\text { objectifying } \\
\text { (Selena Gomez) }\end{array}$} & \multicolumn{2}{|c|}{$\begin{array}{l}\text { Body positive } \\
\text { (Colbie Caillat) }\end{array}$} \\
\hline & $M$ & $S D$ & $M$ & $S D$ \\
\hline General body esteem & 2.70 & 0.88 & 3.10 & 0.99 \\
\hline Other body esteem* & 2.86 & 0.94 & 3.51 & 0.66 \\
\hline Weight body esteem* & 2.27 & 1.05 & 2.97 & 1.02 \\
\hline Body satisfaction & 2.48 & 0.75 & 2.95 & 1.77 \\
\hline
\end{tabular}


American, Multiethnic, or other. Participants were recruited in various ways, including social media announcements, flyer distribution, in-class announcements, and undergraduate psychology classes. Participants received $\$ 10$ for participating in the study.

Measures and materials. Participants viewed one of two music videos: (a) music promoting body positive messages and (b) music promoting body objectifying messages. We wrote lyrics for each condition and created a music video to go with each song. Each song was professionally recorded by the same vocalist and had the same song characteristics (melody, instrumentation, rhythm, pitch, and prosody). The songs differed only by lyrics, which were changed between conditions by adding keywords and phrases to a standard lyrical base (see example in the following text and Appendix for full lyric sets). This was to separate the lyric effect from any effects of the music itself, to allow causal attributions to be made about any between-groups differences. The key words and phrases were carefully chosen to reflect the breadth of the concept of body satisfaction. The body positive video focused on accepting and loving your body regardless of size or shape. For example, the first two lines of the body positive lyric condition read:

Mirror mirror on the wall, I don't want to change at all

because I know I'm beautiful. I have flaws I love them all.

The body objectifying condition video focused on the importance of the physical appearance of the body, in terms of self-worth and other acceptance. The first two lines of the body objectifying condition read:

Mirror mirror on the wall, I just want to change it all.

No one thinks I'm beautiful, so many flaws. I hate them all.

We also created two music videos to go along with the body positive and objectifying lyrics. Both music videos were extremely similar. We hired a professional actress and video team to create the videos. The same actress acted in both videos, and all costumes, camera shots, and settings were exactly the same. The vast majority of scenes were identical in each condition (e.g., the actress walking by a river and looking out over the water). The only noticeable differences in condition were the facial expres- sions, with the actress smiling more in the positive video (which implied her feeling positive about her body) and looking more neutral or sad in the negative video. See Figures 1 and 2 for an example still from the music videos. There were 92 participants in the body positive music condition and 93 in the body objectifying music condition.

Fourteen coders $\left(M_{\mathrm{age}}=22.21,50 \%\right.$ female $)$ viewed and rated both music videos on how body positive each video was on a 5-point scale ranging from 1 (extremely body objectifying) to 5 (extremely body positive). A paired samples $t$ test revealed that coders rated the body positive music video $(M=4.93, S D=.27)$ as being significantly more body positive than the body objectifying video $(M=1.07, S D=.27), t(13)=39.74, p<.001$. Interclass correlations between coders were ICC $=.99$.

\section{Measures and procedures.}

Body esteem and body satisfaction measures. The same body esteem and body satisfaction measures were used as in Study 1 (including the use of the Eating Disorders Scale as a screening measure). Reliability for each measure was similar to Study 1 and can be obtained by contacting Sarah M. Coyne. Additional measures were added as described in the following text.

Implicit body esteem. The Implicit Association Test (IAT) is a measure of implicit associations between different categories (McConnell \& Leibold, 2001; O’Brien, Hunter, Halberstadt, \& Anderson, 2007) and is regularly used as a measure of weight bias (Carels et al., 2014; Sabin, Riskind, \& Nosek, 2015). For the current study, the IAT was designed to measure implicit body esteem. The purpose of including an implicit measure was that body esteem can be somewhat subject to social desirability. Additionally, if participants happened to guess that the study was about body image (which is possible given that we had several measures of body image), this would be a measure that would be completely free from bias. The IAT would signal the cognitive association between concepts, which would indicate an effect regardless of participants' self-reported, explicit body esteem Accordingly, we included an implicit measure of body esteem, which arguably would be a more authentic way to measure the way a person feels about their body.

We used the IAT to measure the reaction time of how participants paired either positive appearance words (beautiful, ideal,

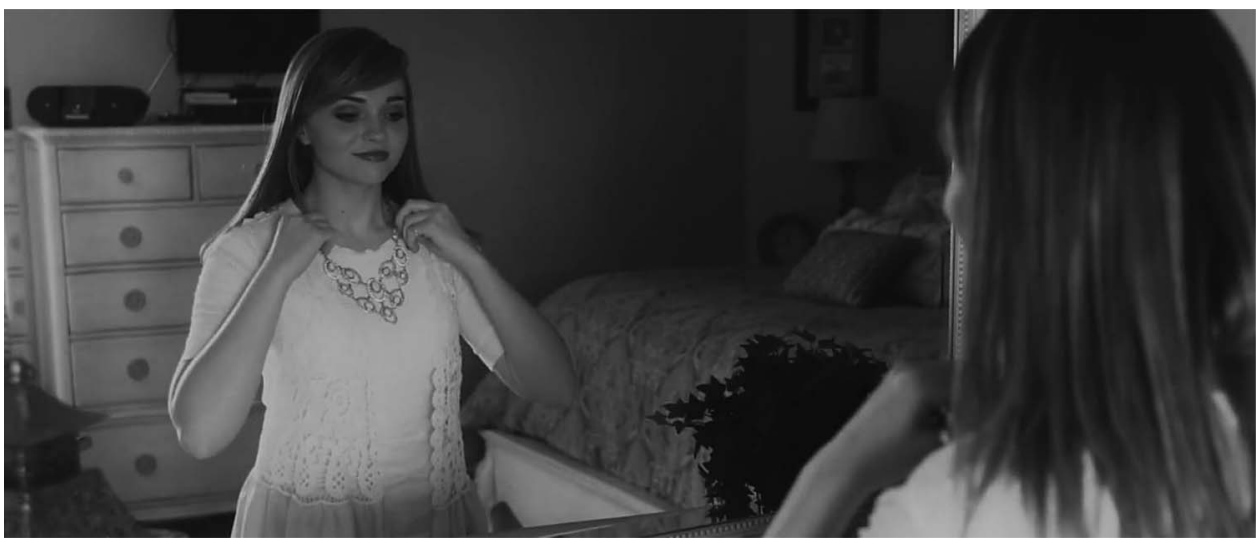

Figure 1. Still from the body positive music video in Study 2. 


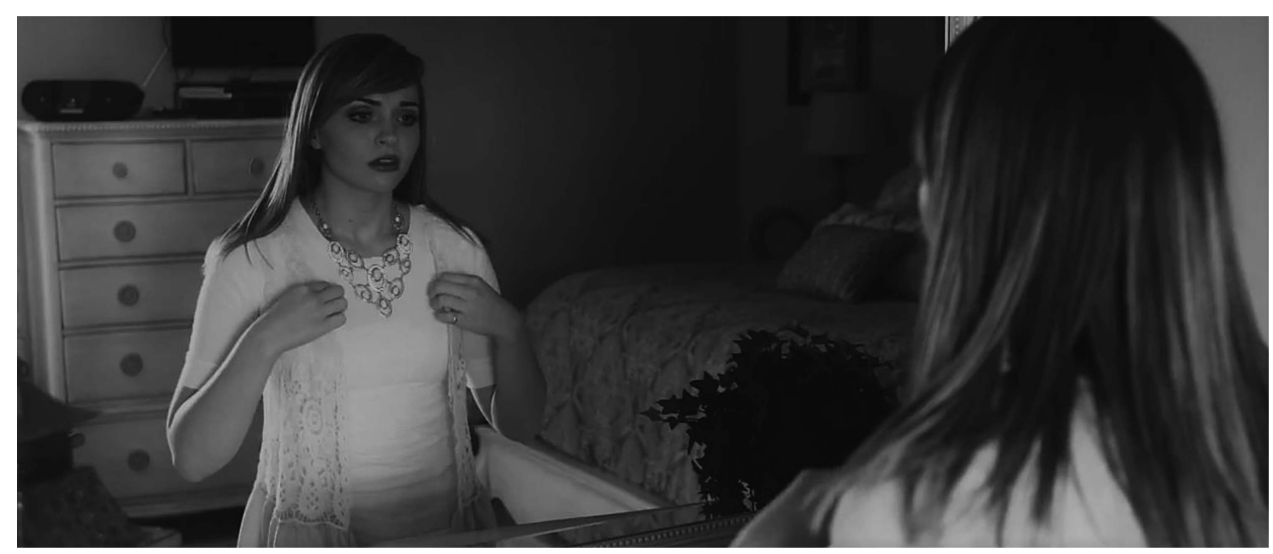

Figure 2. Still from the body objectifying music video in Study 2.

body acceptance, attractive) or negative appearance words (ugly, flawed, repulsive, body shame) with either "self" (I, my, self, me) or "nonself" (other, them, they, not me) related words. The more closely associated the two categories were, the easier it was to respond to them as a single unit. For example, if "beautiful" and "me" were strongly associated, reaction time should be faster when these categories shared a response key. After data collection, individuals who did not meet the cutoff requirements for appropriate speed and accuracy (.10 for both) were excluded to reduce bias.

The body esteem words were coded for the degree of positivity $(1=$ extremely negative to $5=$ extremely positive $)$ and selffocused $(1=$ other, $2=$ neutral, $3=$ self $)$ by 19 independent coders $(M=22.52, S D=1.39,68 \%$ female $)$. A series of paired sample $t$ tests were used to examine whether or not these words were appropriate for the task, applying Bonferroni's correction given the multiple analyses. Analyses revealed that positive body esteem words $(M=4.41, S D=.49)$ were rated significantly more positive than negative body esteem words $(M=1.37, S D=.33)$, $t(18)=17.22, p<.001$. Additionally, self-words $(M=2.99$, $S D=.06)$ were rated as significantly higher for describing the self as compared with non-self-words $(M=1.11, S D=.21), t(18)=$ 32.16, $p<.001$. Interclass correlations were acceptable (ICC $=$ $.78)$.

\section{Procedure.}

Part 1. There were two parts to this study. First, participants were told that the study would be about music and its influences on the overall wellness of women. Participants who passed the screening completed the eating disorders screening measure described previously. Once individuals completed Part 1, they scheduled a time to come to the lab for Part 2, the experimental portion of the study. These two time points were within 1 week of each other.

Part 2. At the beginning of Part 2, the individuals were reminded that they were participating in a study on music and overall wellness. Participants were assigned to view one of the two music videos via a random assignment generator. Participants then listened to one of the music videos using headphones (set at the same level for each condition), completed the IAT, and then completed the other body measures (which were all counterbalanced). Finally, participants were debriefed and were given resources on developing positive body image and being a critical consumer of media.

\section{Results}

A MANCOVA found that condition did not influence any body esteem explicit outcome measures (though means were all in the expected directions). However, an independent samples $t$ test also revealed that participants who saw the body positive video had more positive implicit body esteem, $t(183)=1.96, p=.026, d=$ .29 , than those who saw the body objectifying music videos.

\section{Discussion}

Results from Study 2 suggest that music videos containing positive or objectifying body-related messages influenced implicit body esteem. Participants who viewed a music video containing body positive lyrics displayed higher implicit measures of body esteem compared with people who viewed a music video with body objectifying lyrics. There was no effect on explicit measures of body esteem, though means were in the expected direction. These results are somewhat consistent with the results from Study 1 , though it appears that positive videos tend to influence implicit body esteem more than explicit. Because we created the stimuli ourselves and controlled for many extraneous features of both the music and video, this represents a particularly valid and rigorous test of the hypothesis. Though these results suggest that appearance-based music might have an impact on body esteem, both GLM suggests that there are some potential moderators (termed person characteristics) that might influence individual experiences with music. Theoretically, a long history with body image concerns or a habit of comparing the body with media images might moderate any effects of body positive music. In addition, it is unclear from the Study 2 findings whether the difference found was due to the body positive lyrics or the body objectifying lyrics. Potential moderators and a neutral condition were thus used in the next study.

\section{Study 3}

The vast majority of individuals listen to music outside the context of a music video. A music video provides the listener with visual images, which may arguably exacerbate the impact of lyrics on body esteem. The purpose of Study 3 was to isolate the impact of listening to body positive lyrics (without a music video). There 
were two other major additions to Study 3. First, we composed a song that contained neutral lyrics that would match the two preexisting songs in singer, melody, tempo, and so forth, but would contain no body appearance-related lyrics. Additionally, we examined two potential moderators in this study-prior body esteem and adherence to sociocultural media ideals. How individuals internalize beauty stereotypes in media, or adherence to sociocultural media ideals, is a known moderator to the relationship between body-related media exposure and body esteem (Blowers, Loxton, Grady-Flesser, Occhipinti, \& Dawe, 2003; Cafri, Yamamiya, Brannick, \& Thompson, 2005). Individuals who have shown a greater adherence to sociocultural media ideals have tended to display a larger effect of body-related media on body esteem. In contrast, people with higher appreciation for their bodies have tended to display smaller effects of body-related media on body esteem (Halliwell, Easun, \& Harcourt, 2011). Consequently, the tendency to compare themselves with others may influence the relationship between exposure to positive and negative bodyrelated media and body esteem. We examine both these moderators in the next study.

\section{Method}

Participants. Participants consisted of 237 women ranging from age 18 to $25(M=20.7, S D=1.83)$, who lived in the Western United States. Approximately $87 \%$ were Caucasian, and the other $13 \%$ classified themselves as African American, Hispanic, Asian American, Multiethnic, or other. Participants received $\$ 10$ for participating in the study.

Procedure and materials. The same body esteem measures were used as in Study 2. Reliability for each measure was similar as in Study 2 and can be obtained by contacting Sarah M. Coyne. The procedure for Study 3 was also the same as Study 2 (consisting of an online questionnaire and then a lab-based experimental session $\sim 1$ week later).

The body positive and objectifying songs were used in the current study (see Appendix). However, these were used without the associated music video. An additional song was created to represent a neutral setting. In this song, a person walks through the house and describes what she sees in each room. For example, the first two lines of the neutral condition read:

Mirror mirror on the wall, of the yellow entry hall.

This house is colored manyfold, Some are pastels some are bold.

There were 83 participants in the negative condition, 76 in the neutral, and 78 in the positive condition.

Nineteen independent coders (as described earlier) rated all three of the condition lyrics on how positive the lyrics were on a 5 -point scale ranging from 1 (extremely negative) to 5 (extremely positive) and whether they felt the lyrics were about physical appearance on a 5-point scale ranging from 1 (definitely not about physical appearance) to 5 (definitely about physical appearance). A repeated measures analysis of variance was conducted to identify differences in the three songs. Songs differed by both positivity, $F(2,17)=283.85, p<.001$, and physical appearance, $F(2$, $17)=340.99, p<.001$, all in the expected direction. See Table 2 for means and standard errors for each song. Most importantly, coders rated the body positive lyrics condition as significantly
Table 2

Pilot Study_Means and Standard Errors for Positivity and Physical Appearance for Musical Lyrics, Study 3

\begin{tabular}{|c|c|c|c|c|c|c|}
\hline \multirow[b]{2}{*}{ Ratings } & \multicolumn{2}{|c|}{$\begin{array}{l}\text { Body } \\
\text { positive } \\
\text { lyrics }\end{array}$} & \multicolumn{2}{|c|}{$\begin{array}{c}\text { Body } \\
\text { objectifying } \\
\text { lyrics }\end{array}$} & \multicolumn{2}{|c|}{ Neutral lyrics } \\
\hline & $M$ & $S E$ & $M$ & $S E$ & $M$ & $S E$ \\
\hline Lyric positivity & $4.53^{\mathrm{a}}$ & 0.18 & $1.00^{\mathrm{b}}$ & 0.00 & $4.00^{c}$ & 0.19 \\
\hline Physical appearance & $4.90^{\mathrm{a}}$ & 0.07 & $5.00^{\mathrm{a}}$ & 0.00 & $1.37^{\mathrm{b}}$ & 0.14 \\
\hline
\end{tabular}

Note. Figures with different superscripts indicate a significant difference between condition $(p<.05)$.

more positive than the negative and neutral conditions. Additionally, both the body positive and objectifying lyrics conditions were rated as containing more physical appearance messages than the neutral condition.

Moderators and other questionnaires. Participants completed several questionnaires before their participation in the main study. This included several biographical items, filler items to keep with the cover story, and a few scales that were used as screening questionnaires or as potential moderators.

Sociocultural attitudes toward appearance. Adherence to sociocultural beauty ideals as relayed by media was measured using the general body scale of the Sociocultural Attitudes toward Appearance Questionnaire (Thompson \& Heinberg, 1999). This scale included seven items that examined the degree to which participants compared their body with those in various media (e.g., "I compare my body to the bodies of people who are on TV") using a 5-point Likert-type scale ranging from 1 (definitely disagree) to 5 (definitely agree). Higher scores indicated a greater adherence to sociocultural norms regarding body image. Cronbach's $\alpha$ was acceptable, $\alpha=.89$. For the moderation analysis, scores were dichotomized into low (mean scores 3.00 or lower) or high (mean scores higher than 3.00).

Prior body esteem. We also examined prior body esteem. Participants also responded to one question asking how satisfied they were with their general appearance on a 5-point Likert scale ranging from 1 (very dissatisfied) to 5 (very satisfied).

\section{Results}

A series of bivariate correlations showed that most variables were significantly correlated with each other in the expected direction (see Table 3). In general, implicit measures of body esteem were correlated with most other measures of body esteem and body satisfaction, though at weaker levels. Ethnicity and time spent listening to music were used as covariates in the study.

Body esteem and body satisfaction. A MANCOVA was conducted on the impact of music lyrics on body esteem outcomes, with a significant multivariate effect being found, $F(8,442)=$ $1.99, p=.046, \eta_{\mathrm{p}}^{2}=.04$. An examination of the univariate effects revealed significant main effects of condition for general body esteem, $F(2,224)=5.13, p=.001, \eta_{\mathrm{p}}^{2}=.04$, weight body esteem, $F(2,224)=5.37, p=.005, \eta_{\mathrm{p}}^{2}=.05$, and body satisfaction, $F(2$, 224) $=4.78, p=.009, \eta_{\mathrm{p}}^{2}=.04$. Tukey's post hoc tests were conducted to examine significant differences between groups. Means and standard deviations can be viewed in Table 4. In 
Table 3

Bivariate Correlations Between Main Variables-Study 3

\begin{tabular}{|c|c|c|c|c|c|c|c|}
\hline Variables & 1. & 2. & 3. & 4. & 5. & 6. & 7. \\
\hline 1. General body esteem & - & & & & & & \\
\hline 2. Other body esteem & $.66^{* * * *}$ & - & & & & & \\
\hline 3. Weight body esteem & $.72^{* * * *}$ & $.47^{* * * *}$ & - & & & & \\
\hline 4. Body satisfaction & $.76^{* * * *}$ & $.59^{* * * *}$ & $.79^{* * * *}$ & - & & & \\
\hline 5. Implicit body esteem & $.15^{*}$ & $.19^{* * *}$ & $.14^{*}$ & .11 & - & & \\
\hline 6. Sociocultural attitudes toward media & $-.59^{* * * *}$ & $-.33^{* * * * *}$ & $-.47^{* * * *}$ & $-.43^{* * * *}$ & -.11 & - & \\
\hline 7. Prior body esteem & $.70^{\text {***** }}$ & $.59^{* * * *}$ & $.52^{\text {**** }}$ & $.60^{* * * * *}$ & .23 & $-.39^{* * * * *}$ & - \\
\hline
\end{tabular}

general, there were significant differences between the body objectifying condition compared with the body positive and neutral conditions for almost every variable. There were no significant differences between the body positive and neutral conditions for any outcome.

Moderators were then added to the model. Prior body esteem and sociocultural attitudes did not moderate any outcome.

Implicit body esteem. An ANCOVA was conducted to examine effects of musical lyrics on implicit body esteem. Though the analysis revealed a nonsignificant main effect of condition and no moderation with sociocultural attitudes, there was a significant interaction between condition and prior body esteem $F(2,223)=$ $3.26, p=.04, \eta_{\mathrm{p}}^{2}=.03$. One-way post hoc tests revealed that participants with lower levels of prior body esteem showed worse implicit body esteem after listening to the body objectifying music, $t(75)=3.15, p<.001, d=.76, M=.52, S D=.41$, or the body positive music, $t(72)=1.91, p=.03, d=.53, M=.55, S D=.41$, than those who had higher levels of body esteem at the initial time point $(M=.78, S D=.26 ; M=.73, S D=.30$, respectively). Additionally, there was no difference between low and high prior body esteem for those who listened to the neutral music, $t(70)=$ $85, p=.20, d=.22 ; M=.79, S D=.34 ; M=.72, S D=.30$. In other words, those who reported low body esteem at the initial time point showed worse implicit body esteem after listening to either type of appearance-based music (compared with those who initially had higher levels of body esteem).

\section{Discussion}

The results of this study differ from the results of Studies 1 and 2 in that there was little effect of body positive lyrics on

Table 4

Means and Standard Deviations for Outcome Measures by Music Lyric Condition-Study 3

\begin{tabular}{|c|c|c|c|c|c|c|}
\hline \multirow[b]{3}{*}{ Outcome } & \multicolumn{6}{|c|}{ Condition } \\
\hline & \multicolumn{2}{|c|}{$\begin{array}{c}\text { Body } \\
\text { objectifying }\end{array}$} & \multicolumn{2}{|c|}{ Neutral } & \multicolumn{2}{|c|}{$\begin{array}{l}\text { Body } \\
\text { positive }\end{array}$} \\
\hline & $M$ & $S D$ & $M$ & $S D$ & $M$ & $S D$ \\
\hline General body esteem & $2.36^{\mathrm{a}}$ & 0.66 & $2.56^{\mathrm{b}}$ & 0.63 & $2.66^{\mathrm{a}}$ & 0.58 \\
\hline Other body esteem & $2.42^{\mathrm{a}}$ & 0.64 & $2.57^{\mathrm{a}}$ & 0.55 & $2.56^{\mathrm{a}}$ & 0.59 \\
\hline Weight body esteem & $2.25^{\mathrm{a}}$ & 0.93 & $2.66^{\mathrm{b}}$ & 0.88 & $2.67^{\mathrm{b}}$ & 0.85 \\
\hline Body satisfaction & $3.31^{\mathrm{a}}$ & 0.69 & $3.62^{\mathrm{b}}$ & 0.62 & $3.58^{\mathrm{b}}$ & 0.69 \\
\hline Implicit body esteem & $0.71^{\mathrm{a}}$ & 0.32 & $0.72^{\mathrm{a}}$ & 0.31 & $0.70^{\mathrm{a}}$ & 0.32 \\
\hline
\end{tabular}

Note. Figures with different superscripts indicate a significant difference between condition $(p<.05)$. body esteem outcomes. However, participants who listened to body objectifying lyrics regarding bodies displayed poorer general body esteem and specifically, weight-related body esteem as compared with people who listened to positive lyrics regarding bodies. Additionally, poor body esteem before exposure to the music was related to worse implicit measures of body esteem, regardless of the type of body-related music lyrics listened to by participants. Perhaps, for participants with low body esteem, any reference to physical appearance, whether positive or objectifying, leads to negative reflections on their own bodies and body esteem. Previous researchers have shown that those with low body esteem are at increased risk for negative effects of thin-ideal media (Grabe et al., 2008). The results of the current study support these concerns and extend it to lyrics containing any body image reference (even positive ones).

\section{General Discussion}

The purpose of the current research was to experimentally examine the effects appearance-based music lyrics had on multiple realms of body satisfaction in emerging adult women. A number of hypotheses were supported, though others were mixed. The most consistent finding across every study was that exposure to body objectifying lyrics was associated with poorer body-related outcomes for women. Accordingly, music that sends the message that women's value lies primarily in their body or that their body is not "good enough" can significantly impact the way women feel about themselves. Additionally, across studies, body positive lyrics compared with body objectifying lyrics tended to be related to better body image outcomes for women, especially when paired with a music video. These findings support objectification theory and the broaden-and-build theory to suggest that exposure to body positive messages leads to better body image outcomes than exposure to the many popular songs with lyrics that objectify women. In summary, if emerging adult women are going to choose to listen to appearance-based music, choosing body positive lyrics over objectifying ones are likely a better choice, given the impact on both implicit and explicit feelings of body esteem, depending on the study.

However, in Study 3 there was no noticeable difference between the neutral group and the body positive appearance-related lyric condition. This suggests that listening to a neutral song (about a house) has as large an impact on body esteem as a song that is body positive. This suggests that the body objectifying lyrics were the ones that were driving the relationship between music lyrics and body esteem, as opposed to the positive ones. Additionally, 
those women who struggled with prior body esteem tended to have worse implicit body esteem after listening to either appearancerelated song (as compared with a neutral song). Thus, our optimism for the positive findings are tempered given that listening to even a body positive song is triggering for women who struggle with positive body image. According to the GLM (Buckley \& Anderson, 2006), it is likely that cognitive scripts related to body image are activated in memory after listening to a song that is focused on appearance. A woman with preexisting body image concerns likely has cognitive scripts that are negative concerning her own body image. Listening to a body positive song may activate these scripts, explaining why listening to these lyrics resulted in lower implicit levels of body esteem. This is consistent with objectification theory and supported by a recent study which found that women tended to self-objectify after viewing body positive messages on Instagram (Cohen et al., 2019). Thus, we suggest that women with lower body esteem avoid listening to body-related music, even songs with body positive themes and messages. Media literacy focused on body positivity might focus on changing the cognitive scripts surrounding body image in general, and perhaps a long-term diet of body positive music, especially early in development, might accomplish that aim (and certainly would be supported by the GLM). We only examined short-term effects in the current study, and we hope future research examines the long-term impact of listening to body positive lyrics.

\section{Limitations and Conclusions}

The current studies had several strengths, including multiple studies, an experimental design that allowed the research to control many extemporaneous features, the use of both popular media videos and music lyrics and videos that we designed and produced ourselves (and could control for rhythm, setting, melody, etc.), and both implicit and explicit body esteem measures. However, there were some notable limitations. First, the sample for Studies 2 and 3 were not particularly diverse, with a high majority of White women. It may be that women of different ethnicities may respond very differently to appearance related lyrics. We hope that future research will extend our findings using larger and more diverse populations. Additionally, we focused on emerging adult women. Body image concerns are prevalent during this developmental period, but future research could examine the impact of appearance-related music messages in adolescent girls or older women. Additionally, we included only women in the current studies. Men are certainly influenced by media messages, and many also struggle with body image issues (Barlett, Vowels, \& Saucier, 2008). Accordingly, we hope future research examines the impact of appearance-related music messages on men of all ages. Finally, we prioritized internal validity over ecological validity in two of the three studies. The purpose of this was to control as many extraneous features as possible to be able to examine the impact of specific lyrics on multiple measures of body image. Although the purpose written songs had a sound and feel similar to popular music, they were not songs known to the listeners and may not be a good representation of music heard in the "real world."

Regardless, these studies are the first of their kind, to our knowledge, to examine body positive music lyrics and their impact on body esteem (both explicitly and implicitly). We found that these lyrics do have an impact on the way women feel about their own bodies, though it depends on the content of the lyrics and preexisting body concerns. So perhaps a slight deviation on Christina Aguilera's lyrics from the song "Beautiful" is appropriate here: "You are beautiful, no matter what they say. Words [can] bring you [up or] down."

\section{References}

Aubrey, J. S., \& Frisby, C. M. (2011). Sexual objectification in music videos: A content analysis comparing gender and genre. Mass Communication and Society, 14, 475-501. http://dx.doi.org/10.1080/15205436 .2010 .513468

Barlett, C. P., Vowels, C. L., \& Saucier, D. A. (2008). Meta-analyses of the effects of media images on men's body-image concerns. Journal of Social and Clinical Psychology, 27, 279-310. http://dx.doi.org/10.1521/ jscp.2008.27.3.279

Bell, B. T., Lawton, R., \& Dittmar, H. (2007). The impact of thin models in music videos on adolescent girls' body dissatisfaction. Body Image, 4, 137-145. http://dx.doi.org/10.1016/j.bodyim.2007.02.003

Billboard. (2016, December 12). Billboard's 100 best pop songs of 2016: Critics' picks. Billboard. Retrieved from http://www.billboard.com/ articles/events/year-in-music-2016/7617635/billboard-top-100-popsongs-of-2016

Bissell, K., \& Rask, A. (2010). Real women on real beauty: Selfdiscrepancy, internalisation of the thin ideal, and perceptions of attractiveness and thinness in Dove's Campaign for Real Beauty. International Journal of Advertising: The Review of Marketing Communications, 29, 643-668. http://dx.doi.org/10.2501/S02650 48710201385

Blowers, L. C., Loxton, N. J., Grady-Flesser, M., Occhipinti, S., \& Dawe, S. (2003). The relationship between sociocultural pressure to be thin and body dissatisfaction in preadolescent girls. Eating Behaviors, 4, 229 244. http://dx.doi.org/10.1016/S1471-0153(03)00018-7

Buckley, K. E., \& Anderson, C. A. (2006). A theoretical model of the effects and consequences of playing video games. In P. Vorderer, J. Bryant, P. Vorderer, \& J. Bryant (Eds.), Playing video games: Motives, responses, and consequences (pp. 363-378). Mahwah, NJ: Erlbaum Publishers.

Cafri, G., Yamamiya, Y., Brannick, M., \& Thompson, J. K. (2005). The influence of sociocultural factors on body image: A meta-analysis. Clinical Psychology: Science and Practice, 12, 421-433. http://dx.doi .org/10.1093/clipsy.bpi053

Carels, R. A., Hinman, N. G., Hoffmann, D. A., Burmeister, J. M., Borushok, J. E., Marx, J. M., \& Ashrafioun, L. (2014). Implicit bias about weight and weight loss treatment outcomes. Eating Behaviors, 15, 648-653. http://dx.doi.org/10.1016/j.eatbeh.2014.08.026

Cash, T. F. (2015). Multidimensional Body-Self Relations Questionnaire (MBSRQ). In T. Wade (Ed.), Encyclopedia of feeding and eating disorders (pp. 1-4). Singapore: Springer. http://dx.doi.org/10.1007/978981-287-087-2_3-1

Cohen, R., Fardouly, J., Newton-John, T., \& Slater, A. (2019). \#BoPo on Instagram: An experimental investigation of the effects of viewing body positive content on young women's mood and body image. New Media \& Society, 21, 1546-1564.

Cohen, R., Irwin, L., Newton-John, T., \& Slater, A. (2019). \#bodypositivity: A content analysis of body positive accounts on Instagram. Body Image, 29, 47-57. http://dx.doi.org/10.1016/j.bodyim.2019.02.007

Conley, T. D., \& Ramsey, L. R. (2011). Killing us slowly? Investigating portrayals of women and men in contemporary magazine advertisements. Psychology of Women Quarterly, 35, 469-478. http://dx.doi.org/ $10.1177 / 0361684311413383$

Cotton, M. A., Ball, C., \& Robinson, P. (2003). Four simple questions can help screen for eating disorders. Journal of General Internal Medicine, 18, 53-56. http://dx.doi.org/10.1046/j.1525-1497.2003.20374.x 
Coyne, S. M., Padilla-Walker, L. M., Holmgren, H. G., Davis, E. J., Collier, K. M., Memmott-Elison, M. K., \& Hawkins, A. J. (2018). A meta-analysis of prosocial media on prosocial behavior, aggression, and empathic concern: A multidimensional approach. Developmental Psychology, 54, 331-347. http://dx.doi.org/10.1037/dev0000412

Coyne, S. M., Ward, L. M., Kroff, S. L., Davis, E. J., Holmgren, H. G., Jensen, A. C., . . Essig, L. W. (2019). Contributions of mainstream sexual media exposure to sexual attitudes, perceived peer norms, and sexual behavior: A meta-analysis. Journal of Adolescent Health, 64, 430-436. http://dx.doi.org/10.1016/j.jadohealth.2018.11.016

Crawshaw, T. L. (2019). Rock and rolls: Exploring body positivity at Girls Rock Camp. Fat Studies: An Interdisciplinary Journal of Body Weight and Society, 9, 17-36. http://dx.doi.org/10.1080/21604851.2019 .1603502

Cwynar-Horta, J. (2016). The commodification of the body positive movement on Instagram. Stream: Inspiring Critical Thought, 8, 36-56.

Dohnt, H., \& Tiggemann, M. (2006). The contribution of peer and media influences to the development of body satisfaction and self-esteem in young girls: A prospective study. Developmental Psychology, 42, 929936. http://dx.doi.org/10.1037/0012-1649.42.5.929

Elvers, P., Fischinger, T., \& Steffens, J. (2018). Music listening as selfenhancement: Effects of empowering music on momentary explicit and implicit self-esteem. Psychology of Music, 46, 307-325. http://dx.doi .org/10.1177/0305735617707354

Empire, K. (2016, December 12). Know-it-all by Alessia Cara reviewTeen rebel in search of a better cause. The Guardian. Retrieved from https://www.theguardian.com/music/2016/mar/13/alessia-cara-know-itall-album-review

Flynn, M. A., Craig, C. M., Anderson, C. N., \& Holody, K. J. (2016). Objectification in popular music lyrics: An examination of gender and genre differences. Sex Roles, 75, 164-176. http://dx.doi.org/10.1007/ s11199-016-0592-3

Fredrickson, B. L. (2001). The role of positive emotions in positive psychology. The broaden-and-build theory of positive emotions. American Psychologist, 56, 218-226. http://dx.doi.org/10.1037/0003-066X .56.3.218

Fredrickson, B. L., \& Roberts, T.-A. (1997). Objectification theory: Toward understanding women's lived experiences and mental health risks. Psychology of Women Quarterly, 21, 173-206. http://dx.doi.org/10 .1111/j.1471-6402.1997.tb00108.x

Grabe, S., Ward, L. M., \& Hyde, J. S. (2008). The role of the media in body image concerns among women: A meta-analysis of experimental and correlational studies. Psychological Bulletin, 134, 460-476. http://dx .doi.org/10.1037/0033-2909.134.3.460

Halliwell, E., Easun, A., \& Harcourt, D. (2011). Body dissatisfaction: Can a short media literacy message reduce negative media exposure effects amongst adolescent girls? British Journal of Health Psychology, 16, 396-403. http://dx.doi.org/10.1348/135910710X515714

Harper, B., \& Tiggemann, M. (2008). The effect of thin ideal media images on women's self-objectification, mood, and body image. Sex Roles, 58, 649-657. http://dx.doi.org/10.1007/s11199-007-9379-x

Karsay, K., \& Matthes, J. (2016). Sexually objectifying pop music videos, young women's self-objectification, and selective exposure: A moderated mediation model. Communication Research. Advance online publication. http://dx.doi.org/10.1177/0093650216661434

Karsay, K., Trekels, J., Eggermont, S., \& Vandenbosch, L. (2018). I (don't) respect my body: Investigating the role of media use and selfobjectification on adolescents' positive body image in a cross-national study. Manuscript submitted for publication.

Lennings, H. I. B., \& Warburton, W. A. (2011). The effect of auditory versus visual violent media exposure on aggressive behaviour: The role of song lyrics, video clips and musical tone. Journal of Experimental Social Psychology, 47, 794-799. http://dx.doi.org/10.1016/j.jesp.2011 .02 .006
Lonsdale, A. J., \& North, A. C. (2011). Why do we listen to music? A uses and gratifications analysis. British Journal of Psychology, 102, 108134. http://dx.doi.org/10.1348/000712610X506831

McConnell, A. R., \& Leibold, J. M. (2001). Relations among the implicit association test, discriminatory behavior, and explicit measures of racial attitudes. Journal of Experimental Social Psychology, 37, 435-442. http://dx.doi.org/10.1006/jesp.2000.1470

Mendelson, B. K., Mendelson, M. J., \& White, D. R. (2001). Body-Esteem Scale for adolescents and adults. Journal of Personality Assessment, 76, 90-106. http://dx.doi.org/10.1207/S15327752JPA7601_6

Mischner, I. H., van Schie, H. T., Wigboldus, D. H., van Baaren, R. B., \& Engels, R. C. (2013). Thinking big: The effect of sexually objectifying music videos on bodily self-perception in young women. Body Image, 10, 26-34. http://dx.doi.org/10.1016/j.bodyim.2012.08.004

Molloy, B. L., \& Herzberger, S. D. (1998). Body image and self-esteem: A comparison of African-American and Caucasian women. Sex Roles, 38, 631-643. http://dx.doi.org/10.1023/A:1018782527302

Nelson, S. C., Kling, J., Wängqvist, M., Frisén, A., \& Syed, M. (2018). Identity and the body: Trajectories of body esteem from adolescence to emerging adulthood. Developmental Psychology, 54, 1159-1171. http:// dx.doi.org/10.1037/dev0000435

O'Brien, K. S., Hunter, J. A., Halberstadt, J., \& Anderson, J. (2007). Body image and explicit and implicit anti-fat attitudes: The mediating role of physical appearance comparisons. Body Image, 4, 249-256. http://dx .doi.org/10.1016/j.bodyim.2007.06.001

Paolacci, G., Chandler, J., \& Ipeirotis, P. G. (2010). Running experiments on Amazon Mechanical Turk. Judgment and Decision Making, 5, 411419.

Rideout, V. (2015). The common sense census: Media use by tweens and teens. San Francisco, CA: Common Sense Media. Retrieved from https:// www.commonsensemedia.org/research/the-common-sense-censusmedia-use-by-tweens-and-teens

Sabin, J. A., Riskind, R. G., \& Nosek, B. A. (2015). Health care providers' implicit and explicit attitudes toward lesbian women and gay men. American Journal of Public Health, 105, 1831-1841. http://dx.doi.org/ 10.2105/AJPH.2015.302631

Sastre, A. (2014). Towards a radical body positive: Reading the online "body positive movement." Feminist Media Studies, 14, 929-943. http:// dx.doi.org/10.1080/14680777.2014.883420

Schooler, D., Ward, L. M., Merriwether, A., \& Caruthers, A. (2004). Who's that girl: Television's role in the body image development of young white and black women. Psychology of Women Quarterly, 28, 38-47. http://dx.doi.org/10.1111/j.1471-6402.2004.00121.x

Seligman, M. E., \& Csikszentmihalyi, M. (Eds.). (2014). Positive psychology: An introduction. Flow and the foundations of positive psychology (pp. 279-298). Dordrecht, the Netherlands: Springer.

Slater, A., Varsani, N., \& Diedrichs, P. C. (2017). \#fitspo or \#loveyourself? The impact of fitspiration and self-compassion Instagram images on women's body image, self-compassion, and mood. Body Image, 22, 87-96. http://dx.doi.org/10.1016/j.bodyim.2017.06.004

Thompson, J. K., \& Heinberg, L. J. (1999). The media's influence on body image disturbance and eating disorders: We've reviled them, now can we rehabilitate them? Journal of Social Issues, 55, 339-353. http://dx .doi.org/10.1111/0022-4537.00119

Tiggemann, M., \& McCourt, A. (2013). Body appreciation in adult women: Relationships with age and body satisfaction. Body Image, 10, 624-627. http://dx.doi.org/10.1016/j.bodyim.2013.07.003

Travis, R., Bowman, S. W., Childs, J., \& Villanueva, R. (2016). Musical interactions: Girls who like and use rap music for empowerment. In C. J. Schneider and J. A. Kotarba (Eds.), Symbolic interactionist takes on music (pp. 119-149). Bingley, United Kingdom: Emerald Group Publishing Limited.

Tylka, T. L. (2011). Positive psychology perspectives on body image. 
In T. F. Cash \& L. Smolak (Eds.), Body image: A handbook of science, practice, and prevention (pp. 56-64). New York, NY: Guilford Press.

Tylka, T. L., \& Wood-Barcalow, N. L. (2015). What is and what is not positive body image? Conceptual foundations and construct definition. Body Image, 14, 118-129. http://dx.doi.org/10.1016/j.bodyim.2015.04 .001

Wood-Barcalow, N. L., Tylka, T. L., \& Augustus-Horvath, C. L. (2010). "But I like my body": Positive body image characteristics and a holistic model for young-adult women. Body Image, 7, 106-116. http://dx.doi .org/10.1016/j.bodyim.2010.01.001

Wright, C. L., Carpentier, F. D., Ey, L.-A., Hall, C., Hopper, K. M., \&
Warburton, W. (2018). Report of the Division 46 Task Force on the Sexualization of Popular Music. Washington, DC: American Psychological Association.

Wright, C. L., Carpentier, F. D., Ey, L.-A., Hall, C., Hopper, K. M., \& Warburton, W. A. (2019). Popular-music media literacy: Recommendations for the education curriculum. Policy Insights From the Behavioral and Brain Sciences, 6, 186-193. http://dx.doi.org/10.1177/2372 732219858631

Zhang, Y., Dixon, T. L., \& Conrad, K. (2009). Rap music videos and African American women's body image: The moderating role of ethnic identity. Journal of Communication, 59, 262-278. http://dx.doi.org/10 $.1111 / \mathrm{j} .1460-2466.2009 .01415 . \mathrm{x}$

\section{Appendix}

\section{Music Lyrics for Studies 2 and 3}

\section{Body Positive Lyrics}

Verse: Mirror mirror on the wall

I don't need to change at all

Because I know I'm beautiful

I have flaws, I love them all

Mirror mirror look at me,

I'm satisfied with what I see

I am who I want to be

My looks don't define me

Chorus: I just want to be me

I don't care about what they see

or what they want me to be

All that matters is being me

Verse: Mirror mirror, I feel great

I don't care about my weight
I don't feel the need to hide

Because what matters is inside

Mirror mirror, where to start

Beauty is within the heart

There is nothing wrong with me

I am worthwhile, I am me!

Chorus $\times 2$

\section{Body Objectifying Lyrics}

Verse: Mirror mirror on the wall

I just want to change it all

No one thinks I'm beautiful

So many flaws, I hate them all

Mirror mirror, look at me

I hate everything I see

This isn't who I want be 
My looks don't satisfy me

Chorus: I wish I wasn't me

I don't know what they want from me

Looking good is the only key

All that matters is what they see

Verse: Mirror mirror, I feel bad

My body just makes me sad

I always feel the need to hide

It doesn't matter what's inside

Mirror mirror, where to start

There is nothing in my heart

Everything is wrong with me

I'm not worthwhile, they can see

Chorus $\times 2$

\section{Neutral Lyrics}

Verse: Mirror mirror on the wall

Of the yellow entry hall

This house is colored manyfold

Some are pastels some are bold

Mirror mirror look at me
There I am-yes I can see

And many windows one two three

with flowers underneath the tree

Chorus: There is just so much to see

A bush, a shed, a pot of tea

The lawn it stretches to the road

At my colorful abode

Verse:

Mirror mirror house so great

Flowers line the white front gate

Milk can for a letterbox

Rising up from gray bush rocks

Mirror mirror home's the heart

There is a new work of art

It's a family tapestry

That hangs above the balcony

Chorus $\times 2$

Received September 23, 2019

Revision received December 13, 2019

Accepted December 19, 2019 